\title{
Does the Position of External Branch of Superior Laryngeal Nerve change with the Height of the Patients and the Length of the Larynx
}

\author{
Kithsiri J Senanayake, Ranil Fernando, Sujatha Salgado, Manjula Jayanthi
}

\begin{abstract}
When the external branch of superior laryngeal nerve (EBSLN) crosses the superior thyroid artery closer to thyroid upper pole, the EBSLN has a higher risk of getting damaged. Its anatomical position in relation to thyroid upper pole may vary with changing the height of patient and the length of larynx. We intended to test this hypothesis and predict the risk. Thirty cadavers of both sexes are dissected (29-87 years, mean 69). One cadaver excluded due to a goiter and five nerves were damaged during dissection. Therefore, 53 nerves were studied. The distance from upper pole of thyroid to the point where the nerve crosses the superior thyroid artery (TS) was measured. Cadaver length $(\mathrm{CL})$, cricothyroid length $(\mathrm{CT})$ and the cricohyoid length $(\mathrm{CH})$ measured to the closest millimeter. Correlation of TS with $\mathrm{CL}$, $\mathrm{CT}$ and $\mathrm{CH}$ was measured. The mean distance from the upper pole of the thyroid to the point where EBSLN crosses superior thyroid artery was $6.24 \mathrm{~mm}$ (SD 5.94). On right side, the mean distance was $4.03 \mathrm{~mm}$ (SD 5.34) and, on the left, $8.37 \mathrm{~mm}$ (SD $5.7 \mathrm{~mm}$ ). The difference between two means was significant at $0.05(t=2.82, p=0.007)$. There was a strong correlation between distance from the upper pole of the thyroid to the point where the nerve crosses the superior thyroid artery with $C L(r=0.98)$. There was moderate correlation with the CT and $\mathrm{CH}$ lengths $(r$ $=0.55,0.58$ respectively). The position of EBSLN in relation to thyroid upper pole is strongly correlated with the height of the patient. The EBSLN crosses superior thyroid artery more closely to thyroid upper pole in right side.
\end{abstract}

Keywords: External brach superior Laryngeal nerve, Thyroidectomy, Anatomy.

How to cite this article: Senanayake KJ, Fernando R, Salgado S, Jayanthi M. Does the Position of External Branch of Superior Laryngeal Nerve change with the Height of the Patients and the Length of the Larynx. World J Endocr Surg 2012;4(1):1-2.

\section{Source of support: Nil}

Conflict of interest: None declared

\section{INTRODUCTION}

Damage to the external branch of superior laryngeal nerve (EBSLN) during thyroidectomy is common. ${ }^{1,2}$ Any damage to the EBSLN can cause huskiness, poor volume, fatigue with prolonged use and inability to project or to reach a high pitch: Troublesome symptoms to any patient who uses their voice professionally, such as singers, lawyers, teachers, etc. ${ }^{3}$ Hence, the identification of EBSLN and careful ligation of the thyroid upper pole are vital. When the EBSLN crosses the superior thyroid artery closer to thyroid upper pole, the EBSLN has a higher risk of getting damaged. Its anatomical position in relation to thyroid upper pole may vary with changing the height of patient and the length of larynx. We intended to test this hypothesis and predict the risk.

\section{MATERIALS AND METHODS}

Thirty formalin-fixed cadavers of both sexes, age ranging from 29 to 87 years (mean 69) were dissected. One cadaver was excluded due to a goiter and five nerves were damaged, therefore, 53 nerves (91\%) were studied.

Approval of the ethical committee of University of Kelaniya, Sri Lanka, was taken prior to the dissection of cadavers. The skin flap over the anterior aspect of neck was removed. The sternocleidomastoid, omohyoid and sternothyroid muscles were removed. Thereafter, the superior thyroid artery and upper pole of the thyroid gland were identified. Upper pole of the thyroid was retracted laterally to open the space in the medial side of the thyroid lobe. The EBSLN was explored by a blunt dissection. Once the nerve was encountered, it was traced up to the superior laryngeal nerve to confirm. The distance from the upper pole of thyroid gland to the place where the EBSLN crosses the superior thyroid artery (TS), was measured to the closest millimeter. Cadaver length (CL), cricothyroid length (CT) and the cricohyoid length $(\mathrm{CH})$ were measured to the closest millimeter. Correlation of TS with CL, CT and CH was measured. Statistical analysis was done using the Minitab 14 and Microsoft Excel 2007. The correlation was assessed by the Pearson's technique.

\section{RESULTS}

The mean of distance from upper pole of the thyroid to the point, where EBSLN crosses superior thyroid artery, was $6.24 \mathrm{~mm}$ (SD 5.94). On right side, the mean distance was $4.03 \mathrm{~mm}$ (SD 5.34) and, on the left, $8.37 \mathrm{~mm}$ (SD $5.7 \mathrm{~mm}$ ). The difference between two means was significant at 0.05 $(\mathrm{t}=2.82, \mathrm{p}=0.007$ ) (Fig. 1). There was a strong correlation between distance from the upper pole of the thyroid to the point, where the nerve crosses the superior thyroid artery with CL ( $\mathrm{r}=0.98)$. There was moderate correlation with the $\mathrm{CT}$ and $\mathrm{CH}$ lengths ( $\mathrm{r}=0.55,0.58$ respectively). 


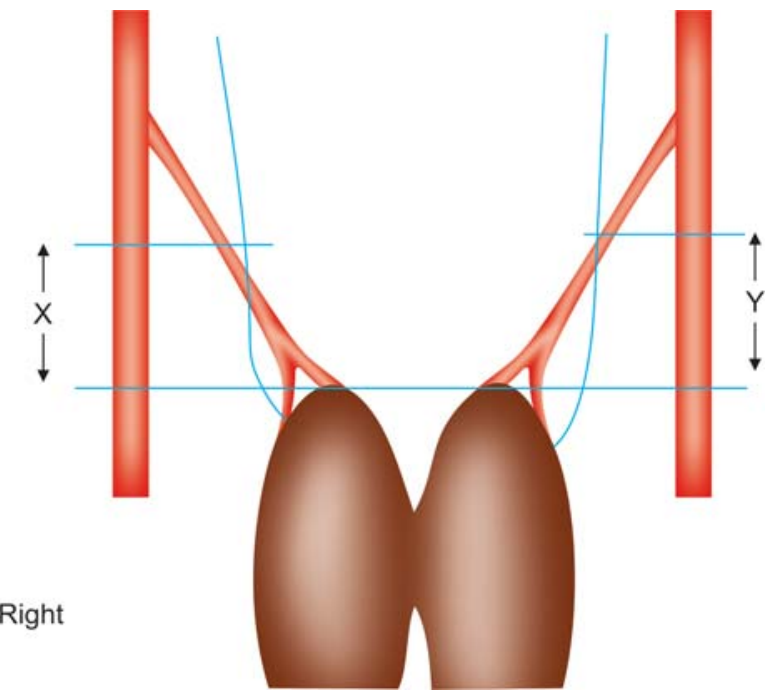

Fig. 1: Mean distance from the point, where the EBSLN crosses the superior thyroid artery to thyroid upper pole in right side $(X=$ $4.03 \mathrm{~mm}$ ). Mean distance from the point, where the EBSLN crosses the superior thyroid artery to thyroid upper pole in right side $(Y=$ $8.37 \mathrm{~mm}$ ). Difference between two means was significant, i.e. EBSLN in right side runs closer to upper pole than left

\section{DISCUSSION}

The current study reveals some of the intrinsic anatomical risk factors of the external branch of the superior laryngeal nerve. When the EBSLN is closer to the upper pole of thyroid, the higher risk of getting it inadvertently damaged. ${ }^{4}$ Individual ligation of superior thyroid artery branches on the thyroid upper pole is currently practiced to prevent EBSLN damaged during thyroidectomy. ${ }^{5}$ However, EBSLN is often neglected during thyroid surgery and more emphasis is given to the identification of recurrent laryngeal nerve and the parathyroid glands. ${ }^{6}$

Preoperative risk group identification would be helpful and this will warn the surgeon to follow meticulous surgical techniques to prevent nerve damage. Risk association with the stature of the patient is shown by Furlan JC et al. ${ }^{7}$ Current study reveals that there is a strong statistical correlation with the height of the patient. Hence, the shorter people are having the EBSLN more closely to the thyroid upper pole. This may be due to human growth and development factors, including embryogenesis. ${ }^{7}$ The topographical differences of EBSLN between ethnic communities could be attributed to the differences in the stature. Correlation with the cricothyroid and cricohyoid length is moderately associated. Data regarding this association in the literature is minimal. The EBSLN is more closely runs to the thyroid upper pole in right side of the neck than left. This fact is not described in literature previously. It is interesting to note that the right side of the neck is having higher risk of getting damaged to the inferior laryngeal nerve due to occasional existence of nonrecurrent laryngeal nerve. ${ }^{8}$ It needs further studies with a larger sample size to get more accurate statistical association.

\section{CONCLUSION}

This preliminary study reveals that the position of EBSLN in relation to thyroid upper pole is strongly correlated with the height of the patient. The EBSLN crosses superior thyroid artery more closely to thyroid upper pole in right side. It needs further studies with a larger sample size to get more accurate association.

\section{REFERENCES}

1. Kark AE, Kissin MW, Auerbach, et al. Voice changes after thyroidectomy: Role of the external laryngeal nerve. BMJ 289;1412-15.

2. Jansson S, Tissell L, Hagne I, et al. Partial superior laryngeal nerve (SLN) lesion before and after thyroid surgery. World J Surg 12;522-27.

3. Zarnegar R, Brunaud L, Clark O. Prevention, evaluation and management of complications following thyroidectomy for thyroid carcinoma. Endocrinol Metab Clin North Am 32(2): 483-502.

4. Cernea CR, Ferraz AR, Nishio S, et al. Surgical anatomy of the external branch of superior laryngeal nerve. Head Neck 1992;14(5):380-83.

5. Wheeler MH. The technique of thyroidectomy. R Soc Med 1998;91(Suppl 33):12-16.

6. Delbridge L. The neglected nerve in thyroid surgery: The case for routine identification of the external nerve (Editorial). ANZ J Surg 2001;71:199.

7. Furlan JC, Cordeiro AC, Brandao LG. Study of some intrinsic factors that can enhance an iatrogenic injury of the external branch of superior laryngeal nerve. Otolaryngol Head Neck Surg 128;396-400.

8. Stewart George R, Mountain John C, Bentley P. Colcock nonrecurrent laryngeal nerve. BJS 59(5);379-81.

\section{ABOUT THE AUTHORS}

\section{Kithsiri J Senanayake (Corresponding Author)}

Lecturer, Department of Surgery, Faculty of Medicine Rajarata University of Sri Lanka, Anuradhapura, Sri Lanka Phone: 094772094131, e-mail: kithsirijanakantha@gmail.com

\section{Ranil Fernando}

Professor, Department of Surgery, Faculty of Medicine, Ragama Sri Lanka

\section{Sujatha Salgado}

Professor, Department of Anatomy, Faculty of Medicine, Ragama Sri Lanka

\section{Manjula Jayanthi}

Demonstrator, Department of Anatomy, Faculty of Medicine Ragama, Sirimavo Bandaranaike Specialised Children's Hospital Peradeniya, Sri Lanka 